\title{
Valor Nutritivo do Feno de Braquiária Amonizado com Uréia ou Inoculado com Pleurotus ostreatus ${ }^{1}$
}

\author{
Patrick Schmidt ${ }^{2}$, Francisco Stefano Wechsler ${ }^{3}$, Fernando Miranda de Vargas Junior ${ }^{4}$, \\ Patrícia Rossi ${ }^{5}$
}

\begin{abstract}
RESUMO - Verificou-se, mediante análises de composição química e ensaio de digestibilidade com ovinos, o efeito dos tratamentos químico (amonização com uréia) e biológico (inoculação com o fungo Pleurotus ostreatus) sobre o valor nutritivo do feno de Brachiaria decumbens. Ambos os tratamentos duraram 42 dias; após esse período, o feno foi seco e moído para fornecimento aos animais. As dietas experimentais foram: feno não tratado (FNT); feno não tratado + uréia (FNT + U); feno inoculado com fungo + uréia (FTB + U); e feno amonizado + feno não tratado (FTQ + FNT). As dietas FNT + U, FTB + U e FTQ + FNT foram isonitrogenadas. Tanto o tratamento químico como o biológico causaram mudanças na composição química do feno. A amonização elevou os teores de proteína bruta (PB) e fibra em detergente ácido (FDA) e reduziu os teores de hemicelulose (HEM) e a proporção de hemicelulose na parede celular (HEMFDN). Já o tratamento biológico tendeu a aumentar o teor de PB; elevou os teores de FDA, lignina (LIG), a proporção de celulose na parede celular (CEL-FDN) e a proporção de lignina na parede celular (LIG-FDN); e reduziu os teores de fibra em detergente neutro (FDN), HEM e HEM-FDN. Entretanto, diminuiu a digestibilidade da matéria seca (MS), FDN, celulose (CEL) e FDA, mas aumentou o consumo, provavelmente em decorrência do menor teor de FDN e menor tamanho médio de partículas, o que causou maior velocidade de passagem. Os tratamentos biológico e químico são alternativas importantes no incremento do valor nutritivo de materiais lignocelulósicos, todavia, os resultados obtidos neste ensaio não foram satisfatórios.
\end{abstract}

Palavras-chave: Brachiaria decumbens, lignina, parede celular, produtos “orgânicos”, tratamento biológico, tratamento químico

\section{Nutritive Value of Brachiaria decumbens Hay Ammoniated with Urea or Innoculated with Pleurotus ostreatus}

\begin{abstract}
The effect of a chemical treatment (ammoniation with urea) or a biological treatment (innoculation with the fungus Pleurotus ostreatus) on the nutritive value of Brachiaria decumbens hay was evaluated by means of chemical analyses and a digestibility trial with sheep. Both treatments lasted 42 days, and thereafter the hay was dried and ground for animal feeding. The experimental diets were the following: untreated Brachiaria hay (FNT); untreated hay plus urea added in the trough (FNT+U); fungus-treated hay plus urea $(\mathrm{FTB}+\mathrm{U})$; and ammoniated hay plus untreated hay $(\mathrm{FTQ}+\mathrm{FNT})$. The FNT+U, FTB+U and FTQ+FNT diets were isonitrogenous. Both the chemical and biological treatments caused changes in hay chemical composition. Ammoniation raised crude protein $(\mathrm{CP})$ and acid detergent fiber (ADF) contents and reduced both hemicellulose(HEM) content and the proportion of hemicelullose in cell walls (HEM-NDF). The biological treatment tended to raise CP; it increased ADF, lignin (LIG), cellulose proportion in cell walls (CEL-FDN) and lignin proportion in cell walls (LIG-FDN); it reduced neutral detergent fiber (NDF), HEM and HEM-NDF. However, it reduced dry matter (DM), NDF, cellulose (CEL) and FDA digestibility; however, it increased intake, probably due to smaller NDF content and smaller particle size, causing a higher rate of passage. Both the biological and chemical treatments are important alternatives in increasing the nutritive value of lignocellulosic materials. Nevertheless, the results obtained in this experiment were not satisfactory.
\end{abstract}

Key Words: biological treatment, Brachiaria decumbens, cell walls, chemical treatment, lignin, "organic" products

\section{Introdução}

Entre as gramíneas tropicais conservadas na forma de feno, destacam-se quantitativamente as do gênero Brachiaria, por apresentar alta produção de matéria seca durante o período das chuvas, em solos de baixa fertilidade, produzindo um feno de baixo custo e amenizando o problema da escassez de volumosos no período seco do ano. A fenação de sobras de pasto e de forragem residual da colheita de sementes, mesmo em estádio avançado de maturidade, também é prática adotada, que evita a queima deste material. Todavia, apesar de boa

\footnotetext{
${ }^{1}$ Parte integrante da dissertação de mestrado do primeiro autor. Trabalho publicado em forma de resumo nos Anais da $38^{a}$ Reunião Anual da Sociedade Brasileira de Zootecnia

2 Zootecnista, Mestre. E.mail: patrick@esalq.usp.br

${ }^{3}$ Prof. Dr. Depto. de Produção e Exploração Animal - FMVZ/Unesp, Botucatu/SP. E.mail: wechsler@fca.unesp.br

4 Zootecnista, Doutor. E.mail: vargasjr@fca.unesp.br

5 Zootecnista. E.mail: rossi_patricia@yahoo.com.br
} 
produção de matéria seca a custo relativamente baixo, estes resíduos caracterizam-se por apresentar alto teor de fibra e baixo teor de proteína bruta (PB), resultando em baixa digestibilidade da matéria seca (MS).

A fração fibrosa das forrageiras é constituída, principalmente, por três compostos ligados entre si: a celulose, a hemicelulose e a lignina, sendo a lignina considerada o principal fator limitante à digestibilidade das forrageiras (Van Soest, 1994).

A elevação do valor nutritivo da forragem é possível mediante tratamentos físicos, químicos ou biológicos, que têm como finalidade principal torná-la mais aproveitável no rúmen, mediante alterações de sua parede celular. Entre os tratamentos químicos, destaca-se a amonização, com amônia anidra ou uréia como fonte de amônia. A amonização promove alterações na composição química dos volumosos, solubilizando a hemicelulose e aumentando o conteúdo de compostos nitrogenados (Reis et al., 1996).

Vários trabalhos têm verificado aumentos nos teores de PB e na digestibilidade após a amonização com uréia (Brown \& Adjei, 1995; Reis et al., 1995; Ballet et al., 1997). Entretanto, os resultados de alterações na fração fibrosa de volumosos tratados com uréia mostram-se inconsistentes (Brown \& Adjei, 1995; Shen et al., 1998) e sugerem a necessidade de novos estudos (Pereira et al., 1990).

O tratamento biológico de volumosos de baixa qualidade surge como uma alternativa ao tratamento químico, em tempos onde os "produtos orgânicos" estão em alta, pois não necessita da adição de substâncias químicas, nem acarreta poluição do ambiente. Este tratamento consiste em inocular microorganismos que degradam a fração fibrosa e aumentam a digestibilidade do material. Os fungos basidiomicetos do gênero Pleurotus degradam celulose, hemicelulose e lignina, sendo a lignina preferencialmente atacada, em comparação aos polissacarídeos (Moyson \& Verachtert, 1991). Alguns trabalhos verificaram aumentos na digestibilidade in vitro da MS (DIVMS) após inoculação com fungos do gênero Pleurotus (Okamoto et al., 1992; Nicolini et al., 1993; Bisaria et al., 1997). Experimentos que avaliem a digestibilidade in vivo de forragens tratadas biologicamente são escassos (Berger et al., 1994).

O objetivo deste trabalho foi verificar o efeito da amonização com uréia como fonte de amônia ou da inoculação com o fungo Pleurotus ostreatus sobre o consumo, balançode nitrogênioe digestibilidade daMS, da PB e da fração fibrosa de feno de Brachiaria decumbens.

\section{Material e Métodos}

\section{Tratamentos do feno}

O feno de Brachiaria decumbens, Stapf., foi produzido na Fazenda Experimental de Ensino e Pesquisa Edgárdia, da Unesp/Botucatu nos meses de março e abril de 2001, com sobras de pastagem, ficando armazenado em galpão até o uso. Para compor os tratamentos, foram aplicados dois processamentos ao feno: químico, baseado em amonização com uréia, segundo a metodologia proposta por Reis \& Rodrigues (1993); e biológico, baseado em inoculação com o fungo Pleurotus ostreatus, conforme metodologia descrita por Adamovic et al. (1998).

Os tratamentos foram realizados de 09/05 a 20/07/2001. A amonização foi feita aplicando-se uréia no nível de 5\% da MS. Usou-se uréia pecuária (45\% de N), diluída em água na proporção de uma parte de uréia para três partes de água. Esta proporção foi calculada para elevar o teor de umidade do feno a $25 \%$. A solução de uréia foi aspergida em camadas de $30 \mathrm{~cm}$ de feno, por meio de uma bomba costal manual. Este processo foi feito em sacos resistentes de polietileno de 400 litros, usando-se $15 \mathrm{~kg}$ de feno por saco. Após a aspersão, os sacos foram lacrados e permaneceram hermeticamente fechados, armazenados em galpão, por 42 dias.

Para a inoculação com o fungo, o feno passou por um pré-tratamento, que consistiu em hidratar o material, submergindo os fardos em água, por 24 horas; em seguida, o feno foi pasteurizado, usando-se uma caldeira a lenha, ligada a uma câmara de pasteurização, onde o feno permaneceu a $65^{\circ} \mathrm{C}$ por oito horas, sendo resfriado gradativamente até atingir a temperatura ambiente ( 72 horas após o início). O objetivo deste pré-tratamento foi propiciar condições adequadas para o crescimento do micélio fúngico.

Após a pasteurização, o feno, com 25,7\% de MS, foi pesado e inoculado com sementes do fungo Pleurotus ostreatus (cepa 97/14) produzidas em serragem, na proporção de $2,5 \%$ do peso úmido, usando-se uma betoneira especial para misturar a semente ao feno. O feno inoculado foi armazenado em sacos de polietileno de 100 litros com pequena aeração $(10 \mathrm{~kg} / \mathrm{saco})$ e mantido a $25^{\circ} \mathrm{C}$, em estufa com temperatura controlada, por 42 dias. Foram colhidas amostras do feno úmido, após a pasteurização, para verificar um possível efeito do pré-tratamento na lixiviação de nutrientes. 
Ambos os materiais, após o período de incubação, foram secos ao sol, visando paralisar os processos de degradação do substrato; moídos em moinho de martelo, com peneira de $6 \mathrm{~mm}$; ensacados; e guardados em galpão ventilado.

\section{Determinação da digestibilidade}

O ensaio de digestibilidade foi realizado no Galpão de Digestibilidade da FMVZ/Unesp - Campus de Botucatu, no período de outubro/2001 a fevereiro/ 2002, usando-se dois quadrados latinos 4 X 4 (Fisher \& Yates, 1971), de acordo com o peso vivo dos animais no início do ensaio.

As dietas experimentais foram: feno não tratado (FNT); feno não tratado + uréia $(\mathrm{FNT}+\mathrm{U})$; feno inoculado com fungo + uréia $(\mathrm{FTB}+\mathrm{U})$; feno amonizado + feno não tratado (FTQ+FNT).

Os fenos das dietas $\mathrm{FNT}+\mathrm{U}$ e $\mathrm{FTB}+\mathrm{U}$ foram suplementados com uma mistura de uréia e sulfato de amônio (9:1) no momento da alimentação, diluída em pequena quantidade de água, aspergida e misturada ao feno, visando atingir o nível de $8 \%$ de PB, considerado não limitante para a ingestão e para a eficiência da digestão ruminal (Van Soest, 1994). A dieta FTQ+FNT foi formada por uma mistura de feno amonizado e feno não tratado (46:54), para atingir o nível de $8 \%$ de $\mathrm{PB}$, visto que o feno tratado com uréia apresentou teor de PB superior a 12\%. Não elevouse a $\mathrm{PB}$ das dietas $\mathrm{FNT}+\mathrm{U}$ e $\mathrm{FTB}+\mathrm{U}$ a $12 \%$, pois, mantido este teor, cerca de $70 \%$ da PB estaria em forma de nitrogênio não-protéico. Desta forma, as dietas FNT+U, FTB+U e FTQ+FNT foram aproximadamente isonitrogenadas.

Usaram-se oito carneiros adultos, mestiços e castrados, vacinados e desverminados, com peso vivo inicial médio de $37,4 \mathrm{~kg}$, providos de bolsa de colheita de fezes e alojados em gaiolas metabólicas individuais, equipadas com cocho para alimentação, bebedouro e saleiro, bem como funil para colheita de urina.

Cada período experimental teve duração de 21 dias, sendo 14 dias de adaptação à dieta e sete dias de colheita de amostras. Os animais foram pesados no início e final de cada período de colheita, em balança digital com precisão de $100 \mathrm{~g}$. Os alimentos foram fornecidos diariamente às 9 e $17 \mathrm{~h}$, ad libitum, na proporção de 40 e $60 \%$ do total diário, respectivamente, mantendo-se aproximadamente $10 \%$ de sobras. A mistura mineral para ovinos foi fornecida ad libitum.

As sobras, as fezes e urina eram colhidas e mensuradas uma vez ao dia, pela manhã. A urina passava por um filtro de algodão e era recolhida em balde, no qual se colocavam diariamente $20 \mathrm{~mL}$ de $\mathrm{HCl}$. Todas as pesagens foram feitas em balança digital com precisão de $1 \mathrm{~g}$, e o volume urinário excretado foi medido em provetas de $1000,250 \mathrm{e}$ $50 \mathrm{~mL}$. Diariamente eram retiradas amostras de dietas, sobras, fezes e urina, separando-se alíquota de $10 \%$ do total fornecido ou colhido.

\section{Preparo e análises das amostras}

Todas as amostras foram congeladas a $-18^{\circ} \mathrm{C}$. As amostras sólidas foram moídas congeladas em nitrogênio líquido, em moinho tipo Wiley com peneira de $1 \mathrm{~mm}$, visando evitar a perda de $\mathrm{N}$ amoniacal (Schneider \& Flatt, 1975). A seguir, foram compostas e homogeneizadas, retirando-se uma sub-amostra por animal em cada período. A urina foi descongelada, composta, homogeneizada, sub-amostrada e novamente mantida congelada até as análises químicas.

As análises químicas para determinação de MS, fibra em detergente neutro (FDN), fibra em detergente ácido (FDA), celulose (CEL) e lignina (LIG) foram realizadas no Laboratório de Nutrição Animal da FMVZ/Unesp, segundo metodologia descrita por Silva (1990), com quatro repetições, à exceção da FDN, cuja análise foi efetuada com cinco repetições. Para a determinação da PB seguiu-se o método microKjeldahl descrito por AOAC (1990), com as seguintes modificações: o catalisador foi o sulfato de cobre, e na titulação usou-se ácido sulfúrico $0,05 \mathrm{~N}$. O teor de hemicelulose (HEM) foi calculado como a diferença entre os teores de FDN e FDA. Calcularam-se também as proporções de hemicelulose (HEM-FDN), celulose (CEL-FDN) e lignina (LIG-FDN) na parede celular. $\mathrm{Na}$ determinação da FDN das fezes, adicionou-se $0,5 \mathrm{~g}$ de sulfito de sódio por amostra, visando eliminar o efeito de possíveis contaminações com pêlos.

Para determinação do teor de $\mathrm{N}$ da urina, usou-se $1 \mathrm{~mL}$ para os animais que excretaram volume menor que a média do período e $2 \mathrm{~mL}$ para os animais que urinaram volume maior que a média.

As análises de tamanho de partícula do feno não tratado e dos fenos tratados foram realizadas em triplicata, no Laboratório de Poluição Ambiental da FCA/Unesp, usando-se $25 \mathrm{~g}$ de amostra, agitadas por 10 minutos em agitador automático, com peneiras de 4,$00 ; 2,00 ; 1,41 ; 1,00$ e $0,50 \mathrm{~mm}$.

\section{Variáveis e metodologia estatística}

Os coeficientes de digestibilidade aparente foram calculados consoante Schneider \& Flatt (1975). Tam- 
bém se estimou, por diferença, a digestibilidade do feno amonizado (FTQ), com base nos coeficientes das dietas FNT+U e FTQ+FNT.

As variáveis avaliadas foram: composição e granulometria do feno; consumo voluntário de MS; digestibilidade aparente da MS, PB, FDN, FDA, CEL e HEM; e balanço de nitrogênio.

Para análise estatística dos dados de composição química do feno não tratado e dos fenos tratados, usou-se o Modelo I:

$$
\mathrm{y}_{\mathrm{ij}}=\mathrm{m}+\mathrm{t}_{\mathrm{i}}+\mathrm{e}_{\mathrm{ij}}
$$

em que: $\mathrm{y}_{\mathrm{ij}}=$ teor do componente na j-ésima amostra do i-ésimo feno; $m=$ constante; $t_{i}=$ efeito fixo do i-ésimo feno $\left(\mathrm{O}_{\mathrm{i}}=0\right)$; $\mathrm{e}_{\mathrm{ij}}=$ erro experimental associado à observação $y_{i j}, e_{i j} \sim$ NID $\left(0, \sigma^{2}{ }_{e}\right)$.

No Modelo I, os efeitos dos tratamentos foram desdobrados mediante os seguintes contrastes: 1 . feno não tratado (FNT) vs. feno tratado biologicamente (FTB) (efeito do fungo); 2. FNT vs. feno tratado quimicamente (FTQ) (efeito da amonização); 3. FTB vs. FTQ (diferença entre o tratamento biológico e o químico).

Para análise estatística dos dados de consumo, digestibilidade aparente, e balanço de nitrogênio usouse o Modelo II:

$$
\mathrm{y}_{\mathrm{ijkl}}=\mathrm{m}+\mathrm{q}_{\mathrm{i}}+\mathrm{a}_{\mathrm{ij}}+\mathrm{p}_{\mathrm{k}}+\mathrm{d}_{\mathrm{l}}+\mathrm{e}_{\mathrm{ijkl}}
$$

em que $y_{i j k l}=$ variável observada no animal $j$, que recebeu a dieta 1 , no período $\mathrm{k}$ e no quadrado $\mathrm{i}$; $\mathrm{m}=$ constante; $\mathrm{q}_{\mathrm{i}}=$ efeito fixo do quadrado i $\left(\Sigma \mathrm{q}_{\mathrm{i}}=0\right)$; $\mathrm{a}_{\mathrm{ij}}=$ efeito aleatório do animal $\mathrm{j}$ dentro do quadrado $\mathrm{i}, \mathrm{a}_{\mathrm{ij}} \sim \mathrm{NID}\left(0, \sigma_{\mathrm{a}}^{2}\right) ; \mathrm{p}_{\mathrm{k}}=$ efeito do período $\mathrm{k}\left(\Sigma \mathrm{p}_{\mathrm{k}}=0\right)$; $\mathrm{d}_{1}=$ efeito da dieta $1\left(\Sigma \mathrm{d}_{1}=0\right) ; \mathrm{e}_{\mathrm{ijkl}}=$ erro experimental associado à parcela $\mathrm{y}_{\mathrm{ijkl}}, \mathrm{e}_{\mathrm{ijkl}} \sim \mathrm{NID}\left(0, \sigma_{\mathrm{e}}^{2}\right)$.

Os efeitos de dietas no Modelo II foram desdobrados por meio dos seguintes contrastes linearmente independentes: 1. FNT versus $\mathrm{FNT}+\mathrm{U}$ (efeito da adição de uréia); 2 . FNT+U versus $\mathrm{FTB}+\mathrm{U}$ (efeito da inoculação com fungo); 3 . FNT+U versus FTQ+FNT (efeito da amonização com uréia); e 4. FTB+U versus FTQ+FNT (inoculação com fungo versus amonização com uréia).

Para efeito de significância estatística, as variáveis foram divididas em cinco grupos: composição química; digestibilidade; consumo de MS; consumo de MS digestível (MSD); e balanço de nitrogênio. Para proteção da taxa de erro do tipo I dentro de cada grupo, considerou-se significante um resultado para o qual $\mathrm{P}<0,05 / \mathrm{c} / \mathrm{v}$, em que $\mathrm{c}=$ número de contrastes aplicados; e v = número de variáveis que constituíam o grupo. Considerou-se como tendência um resultado para o qual $\mathrm{P}<0,15 / \mathrm{c} / \mathrm{v}$.

As análises estatísticas foram realizadas por meio do programa GLM do SAS (1996).

\section{Resultados e Discussão}

\section{Composição química}

A composição química do feno não tratado (FNT), tratado biologicamente com Pleurotus ostreatus (FTB), ou quimicamente com uréia (FTQ), está apresentada na Tabela 1.

O FTB acarretou diminuição dos teores de FDN e HEM, bem como da proporção HEM-FDN; e elevou os teores de FDA e LIG, bem como as proporções CEL-FDN e LIG-FDN. Também se observou, neste tratamento, tendência de aumento no teor de PB.

O FTQ aumentou os teores de PB e FDA e diminuiu os teores de HEM, bem como a proporção HEM-FDN.

Comparando-se o FTB com o FTQ, observa-se que este último apresentou maiores teores de PB, FDN e HEM, bem como maior proporção HEMFDN; e menor teor de FDA, bem como menor proporção CEL-FDN.

$\mathrm{O}$ tratamento biológico reduziu o teor de FDN em $5 \%$ e o de HEM em $30 \%$; e elevou o de LIG em $20 \%$, além de tender a elevar o teor de PB em 13\%. Estes resultados são comparáveis aos obtidos por Schmidt et al. (2003), que verificaram redução média de $15,3 \%$ no teor de FDN e 33,0\% no teor de HEM, com elevação de $39 \%$ no teor de PB, após a incubação do feno de braquiária por 35 dias, com P. ostreatus, nas mesmas condições. Desta forma, pode-se afirmar que o tratamento biológico diminui os teores de FDN e hemicelulose e aumenta o de PB.

Visando verificar se as mudanças evidenciadas no FTB poderiam ser atribuídas à lixiviação de nutrientes, realizou-se também análise bromatológica da composição química do feno úmido, determinada após a imersão em água e pasteurização. Não se observaram diferenças significativas em relação ao FNT, indicando que as mudanças são atribuídas ao crescimento do micélio fúngico.

A amonização elevou o teor de PB em 259\% e o de FDA em 3,0\% e reduziu o teor de HEM e a proporção HEM-FDN em 5\%. Reis et al. (2001a) e 
Reis et al. (2001b) verificaram, após o tratamento de feno de $B$. decumbens com uréia $(5,4 \%$ da MS), aumento de 193 e $324 \%$ no teor de PB, respectivamente, porém nenhuma alteração significativa nos constituintes da parede celular.

A elevação do teor de proteína PB no feno com a amonização está ligada à retenção de nitrogênio, e esta, à atividade ureolítica responsável pela transformação da uréia em amônia. A retenção de nitrogênio (N) observada no FTQ foi $76 \%$. Reis et al. (1995), aplicando uréia no feno de Brachiaria brizantha (5,4\% da MS), verificaram retenção de 99,83\% do N, evidenciando baixa hidrólise da uréia, com baixa liberação de amônia. Aplicando a mesma dose de uréia a feno de $B$. decumbens, Rosa et al. (1998), Reis et al. (2001a) e Reis et al. (2001b) observaram retenção de 53,6; 60,5; e $47 \%$ do $\mathrm{N}$ aplicado, respectivamente.

\section{Consumo}

O consumo médio de MS, expresso tanto em percentagem do peso vivo (PV) como por unidade de peso metabólico ( $\mathrm{PV}^{0,75}$ ), está apresentado na Tabela 2. Aplicando-se a equação y $=74,4+0,877$ (FDN) - 0,017 (FDN) ${ }^{2}$ (NRC, 1987), obtiveram-se os valores preditos para o consumo de MS: 31,6; 34,$1 ; 41,1 ; 31,1$ e $30,5 \mathrm{~g} / \mathrm{kg}(\mathrm{PV})^{0,75}$, para os tratamentos FNT, FNT+U, FTB+U e FTQ+FNT, bem como para o consumo estimado do FTQ. Verifica-se que os consumos observados ficaram nitidamente acima dos preditos.

A adição de uréia (FNT+U) ou feno amonizado (FTQ+FNT) não promoveu efeito observável na ingestão de MS. Em contraste, os animais alimentados com a dieta $\mathrm{FTB}+\mathrm{U}$ apresentaram maior consumo, por unidade de peso vivo e peso metabólico, em relação ao FNT+U e ao FTQ+FNT.

Tabela 1 - Composição química dos fenos tratados e do feno não tratado (\% da MS)

Table 1 - Chemical composition of the treated and not treated hay (\%DM)

\begin{tabular}{|c|c|c|c|c|c|c|c|}
\hline \multirow{2}{*}{$\begin{array}{l}\text { Variáveis }^{2} \\
\text { Variable }^{2}\end{array}$} & \multicolumn{3}{|c|}{$\begin{array}{c}\text { Fenos } \\
\text { Hays }^{1}\end{array}$} & \multirow[b]{2}{*}{$\mathrm{EP}^{3}$} & \multicolumn{3}{|c|}{$\begin{array}{c}\text { Contrastes } \\
\text { Contrasts }\end{array}$} \\
\hline & FNT & FTB & FTQ & & FNT vs FTB & FNT vs FTQ & FTB vs FTQ \\
\hline PB & 3,9 & 4,5 & 14,0 & 0,24 & $*$ & $* *$ & $* *$ \\
\hline$C P$ & & & & & & & \\
\hline $\begin{array}{l}\mathrm{FDN} \\
N D F\end{array}$ & 82,2 & 78,3 & 82,8 & 0,69 & $* *$ & n.s. & $* *$ \\
\hline $\begin{array}{l}\text { FDA } \\
A D F\end{array}$ & 50,5 & 55,8 & 52,0 & 0,32 & $* *$ & $* *$ & $* *$ \\
\hline HEM & 32,0 & 22,5 & 30,4 & 0,45 & $* *$ & $* *$ & $* *$ \\
\hline CEL & 39,6 & 40,4 & 39,3 & 0,67 & n.s. & n.s. & n.s. \\
\hline LIG & 7,9 & 9,9 & 9,5 & 0,67 & $* *$ & n.s. & n.s. \\
\hline $\begin{array}{l}\text { HEM-FDN } \\
H E M-N D F\end{array}$ & 38,8 & 28,7 & 36,9 & 0,45 & $* *$ & $* *$ & $* *$ \\
\hline $\begin{array}{l}\text { CEL-FDN } \\
C E L-N D F\end{array}$ & 48,1 & 51,6 & 47,7 & 0,85 & $* *$ & n.s. & $* *$ \\
\hline $\begin{array}{l}\text { LIG-FDN } \\
L I G-N D F\end{array}$ & 9,6 & 12,7 & 11,6 & 0,81 & $* *$ & n.s. & n.s. \\
\hline
\end{tabular}

${ }^{1}$ FNT = feno de Brachiaria decumbens não tratado; FTB = feno de $B$. decumbens tratado biologicamente com Pleurotus ostreatus; FTQ = feno de $B$. decumbens tratado quimicamente com uréia.

${ }^{2} \mathrm{MS}=$ matéria seca; $\mathrm{PB}$ = proteína bruta; $\mathrm{FDN}$ = fibra em detergente neutro; FDA = fibra em detergente ácido; $\mathrm{HEM}=$ hemicelulose $\mathrm{CEL}=$ celulose $\mathrm{LIG}=$ lignina; $\mathrm{HEM}-\mathrm{FDN}=$ percentagem de hemicelulose na FDN; CEL-FDN = percentagem de celulose na FDN; LIG-FDN = percentagem de lignina na FDN.

${ }^{3} \mathrm{EP}=$ erro-padrão da média

*Tendência: $P<0,15 / 3 / 9=0,00556$; ${ }^{*}$ significativo: $P<0,05 / 3 / 9=0,00185 ;$ n.s. $=$ não significativo: $P \geq 0,00556$.

${ }^{1} F N T=$ not treated Brachiaria decumbens hay; $F T B=B$. decumbens hay biologically treated with Pleurotus ostreatus; $F T Q=$ chemical treatment of $B$. decumbens hay using urea.

${ }^{2} D M=$ dry matter; $C P=$ crude protein; $N D F=$ neutral detergent fiber; $A D F=$ acid detergent fiber; $H E M=$ hemicellulose; $C E L=$ cellulose $; L I G=$ lignin; $H E M-N D F=$ percentage of hemicellulose in NDF; $C E L-N D F=$ percentage of cellulose in NDF; LIG- NDF = percentage of lignin in NDF.

${ }^{3} E P=$ standard error of mean.

* Trend: $P<0.15 / 3 / 9=0.00556$; ${ }^{* *}$ significant: $P<0.05 / 3 / 9=0.00185 ;$ n.s. $=$ not significant: $P \geq 0.00556$. 
A ausência de elevação no consumo do $\mathrm{FNT}+\mathrm{U}$, em relação ao FNT, pode ser devida ao déficit de energia prontamente digestível na dieta. De acordo com NRC (1976), a suplementação com uréia de forragens com alto teor de fibra aumenta substancialmente a ingestão de MS, desde que níveis adequados de carboidratos fermentescíveis e minerais estejam disponíveis, para elevar o uso microbiano da uréia e a taxa de degradação da forragem.

O consumo observado para o FTQ+FNT difere do resultado obtido por Rosa et al. (1998), que verificaram aumento de $28,7 \%$ no consumo de feno de braquiária amonizado com uréia $(5,4 \%$ da MS). A ausência de alteração observada no consumo de FTQ+FNT pode ser decorrente da mistura do feno amonizado com o feno não tratado (46:54), para reduzir o teor de $\mathrm{PB}$ a $8 \%$. Os valores calculados para o feno amonizado, embora não possam ser testados estatisticamente, apontam para elevação de aproximadamente $11 \%$, em relação ao FNT, e $6 \%$, em relação ao $\mathrm{FNT}+\mathrm{U}$. Estes resultados sugerem que possível aumento no consumo, em decorrência da amonização, dever-se-ia ao aumento no teor de nitrogênio, bem como à ação sobre a parede celular.

\section{Digestibilidade}

Os coeficientes de digestibilidade aparente das dietas e do feno amonizado são apresentados na Tabela 3 .
Observa-se que a suplementação com uréia do feno não tratado $(\mathrm{FNT}+\mathrm{U})$ alterou apenas o coeficiente de digestibilidade aparente da PB, não exercendo influência detectável sobre a digestibilidade dos demais componentes, provavelmente pela assincronia entre fermentação de carboidratos e liberação da amônia, já discutida.

OFTQ+FNT não mostrou efeito sobre o coeficiente de digestibilidade de nenhuma das frações estudadas, se comparado ao FNT+U. A digestibilidade do feno amonizado puro (FTQ), calculada por diferença, embora não possa ser testada estatisticamente, aponta para uma elevação no coeficiente de digestibilidade da FDA (8\%) e da CEL (11\%), em relação ao FNT + U. Estes resultados indicam que, nas condições em que foi realizado o tratamento químico neste experimento, as mudanças verificadas na composição química do feno amonizado (Tabela 1) não se mostraram suficientes para alterar claramente o perfil de digestão desse feno; o aumento no teor de $\mathrm{N}$ não parece ter proporcionado maior atividade microbiana no rúmen, pois não se observou aumento na digestibilidade da MS, nem melhora evidente da digestibilidade da parede celular.

$\mathrm{O}$ FTB $+\mathrm{U}$ reduziu os coeficientes de digestibilidade da MS (25,2\%), FDN (20,9\%), FDA $(22,1 \%)$ e CEL $(14,1 \%)$, em relação ao $\mathrm{FNT}+\mathrm{U}$, ou ao FTQ+FNT. Observando os dados das Tabelas 1, 2 e 3, verifica-se que o tratamento biológico reduziu

Tabela 2 - Consumo médio de MS, em \% do peso vivo (PV) e por unidade de peso metabólico ( $\left.\mathrm{PV}^{0,75}\right)$ Table 2 - Mean intake of DM, as a percentage of body weight (BW) \% and on basis of metabolic weight $\left(B W^{0,75}\right)$

\begin{tabular}{|c|c|c|c|c|c|c|c|c|c|c|}
\hline \multirow{2}{*}{$\begin{array}{l}\text { Consumo } \\
\text { Intake }\end{array}$} & \multicolumn{4}{|c|}{$\begin{array}{c}\text { Dietas }^{1} \\
\text { Diets }\end{array}$} & \multirow[b]{2}{*}{$\mathrm{FTQ}^{3}$} & \multirow[b]{2}{*}{$\mathrm{EP}^{4}$} & \multicolumn{4}{|c|}{$\begin{array}{c}\text { Contrastes }^{2} \\
\text { Contrasts }^{2}\end{array}$} \\
\hline & FNT & $\mathrm{FNT}+\mathrm{U}$ & $\mathrm{FTB}+\mathrm{U}$ & FTQ+FNT & & & 1 & 2 & 3 & 4 \\
\hline$\%$ do PV & 1,74 & 1,83 & 2,35 & 1,88 & 1,94 & 0,09 & n.s. & $* *$ & n.s. & $* *$ \\
\hline \multicolumn{11}{|l|}{$\%$ of $B W$} \\
\hline $\begin{array}{l}\mathrm{g} / \mathrm{kg} \mathrm{PV} 0,75 \\
\mathrm{~g} / \mathrm{kg} B W^{0,75}\end{array}$ & 42,9 & 45,4 & 57,5 & 46,5 & 47,8 & 2,23 & n.s. & $* *$ & n.s. & $* *$ \\
\hline
\end{tabular}

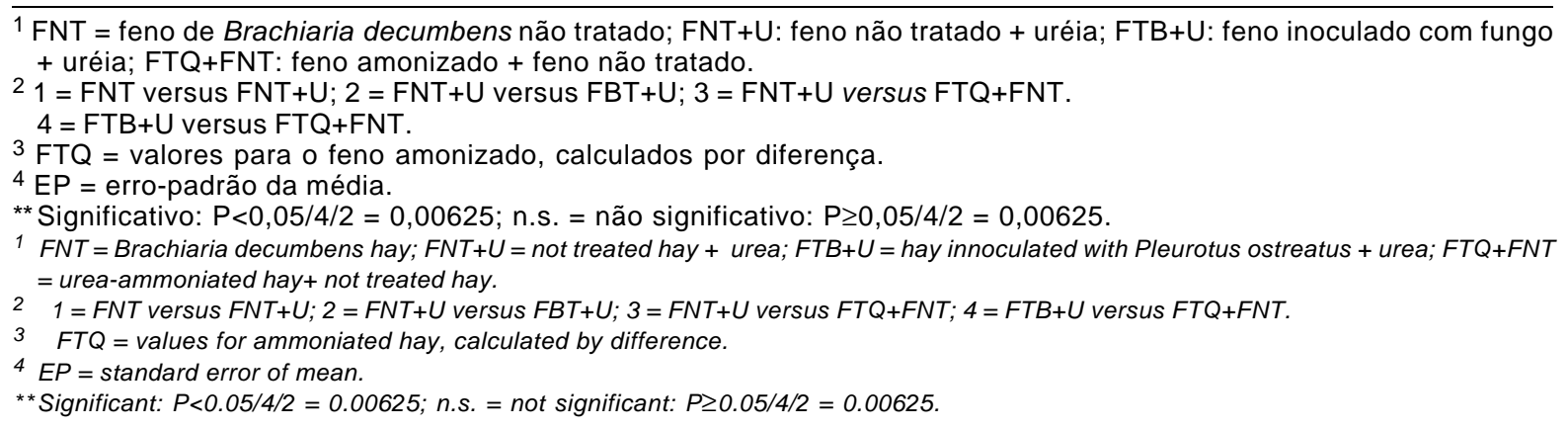


os teores de FDN e HEM; elevou os teores de LIG e FDA; elevou a proporção LIG-FDN; e aumentou o consumo; entretanto, reduziu a digestibilidade. Este comportamento pode ser explicado, em parte, pela alteração na composição química: a despeito da redução do teor de FDN, observou-se aumento no teor de lignina da parede celular; e, por outra parte, por uma possível elevação da taxa de passagem, decorrente do menor tamanho médio de partícula observado neste tipo de feno (Tabela 4). Verifica-se claramente que o FTB apresentou menor tamanho médio de partículas, sendo que $77,41 \%$ destas ficaram abaixo de $1 \mathrm{~mm}$. Esse efeito no tamanho é decorrente da ação do fungo sobre o substrato, que tornou o feno mais macio e provavelmente acarretou a quebra deste em partículas diminutas, durante a moagem.

A amonização também influenciou o tamanho médio das partículas após a moagem, principalmente no tocante às frações maiores (peneira de $4 \mathrm{~mm}$ ), ficando esse feno em uma condição intermediária entre o feno não tratado e o feno tratado biologicamente. Este efeito ajuda a explicar a tendência de aumento no consumo estimado para o FTQ, discutida anteriormente.

Wilson \& Hatfield (1997), citados por Hughes et al. (1998), sugerem que o arranjo arquitetural dos tecidos e os padrões de lignificação entre e dentro dos tecidos possivelmente explicam diferenças em degradação e no potencial de redução de tamanho de partículas em plantas. Dessa forma, apesar de ter sido usada a mesma peneira, o efeito físico de tratamento pode ter sido um fator que afetou os níveis de consumo e digestibilidade.

Aumentos na ingestão são comumente observados quando o tamanho médio de partículas é reduzido, com máxima ingestão alcançada quando o tamanho médio de partículas é de $1 \mathrm{~mm}$ ou menor (NRC, 1996).

Berger et al. (1994), revisando a literatura sobre processamentos físicos, afirmam que a diminuição na digestibilidade de forragens moídas é primariamente devida à redução na digestão da fibra, uma vez que estudos in vitro mostram que a moagem fina de forragens aumenta a degradabilidade da parede celular, enquanto estudos in vivo, geralmente, mostram

Tabela 3 - Coeficientes de digestibilidade aparente das frações dos fenos tratados e do feno não tratado Table 3 - Apparent digestibility coefficients of chemical fractions from treated and not treated hays

\begin{tabular}{|c|c|c|c|c|c|c|c|c|c|c|}
\hline \multirow{2}{*}{$\begin{array}{l}\text { Variáveis } \\
\text { Variable }\end{array}$} & \multicolumn{4}{|c|}{$\begin{array}{c}\text { Dietas }^{1} \\
\text { Diets }^{1}\end{array}$} & \multirow[b]{2}{*}{$\mathrm{FTQ}^{4}$} & \multirow[b]{2}{*}{$\mathrm{EP}^{5}$} & \multicolumn{4}{|c|}{$\begin{array}{c}\text { Contrastes }^{2} \\
\text { Contrasts }^{2}\end{array}$} \\
\hline & FNT & $\mathrm{FNT}+\mathrm{U}$ & $\mathrm{FTB}+\mathrm{U}$ & FTQ+FNT & & & 1 & 2 & 3 & 4 \\
\hline $\begin{array}{l}\mathrm{MS}^{3} \\
D M^{3}\end{array}$ & 40,9 & 43,1 & 32,3 & 44,4 & 45,5 & 1,73 & n.s. & $* *$ & n.s. & $*$ \\
\hline $\begin{array}{l}\mathrm{PB} \\
C P\end{array}$ & 0,36 & 60,4 & 48,1 & 51,4 & 50,3 & 3,33 & $* *$ & n.s. & n.s. & $\mathrm{n} . \mathrm{s}$. \\
\hline $\begin{array}{l}\text { FDN } \\
N D F\end{array}$ & 52,3 & 53,1 & 42,0 & 54,5 & 55,6 & 1,45 & n.s. & $* *$ & n.s. & $*$ \\
\hline $\begin{array}{l}\text { FDA } \\
A D F\end{array}$ & 50,1 & 50,7 & 39,5 & 52,6 & 54,8 & 1,65 & n.s. & $* *$ & n.s. & $*$ \\
\hline $\begin{array}{l}\text { HEM } \\
H E M\end{array}$ & 55,7 & 56,9 & 47,8 & 57,4 & 57,0 & 2,27 & n.s. & n.s. & n.s. & $\mathrm{n} . \mathrm{s}$. \\
\hline $\begin{array}{l}\text { CEL } \\
C E L\end{array}$ & 58,3 & 59,2 & 50,8 & 62,3 & 65,8 & 1,56 & n.s. & $* *$ & n.s. & $*$ \\
\hline
\end{tabular}

\footnotetext{
${ }^{1} \mathrm{FNT}$ = feno de Brachiaria decumbens não tratado; FNT+U: feno não tratado + uréia; FTB+U: feno inoculado com fungo + uréia; FTQ+FNT: feno amonizado + feno não tratado.

$21=$ FNT versus FNT+U; $2=F N T+U$ versus FBT+U; $3=F N T+U$ versus FTQ+FNT; $4=F T B+U$ versus FTQ+FNT.

$3 \mathrm{MS}=$ matéria seca; $\mathrm{PB}=$ proteína bruta; FDN = fibra em detergente neutro; FDA = fibra em detergente ácido; $\mathrm{HEM}=$ hemicelulose $; \mathrm{CEL}=$ celulose.

4 FTQ = valores para o feno amonizado, calculados por diferença.

$5 \mathrm{EP}=$ erro-padrão da média.

** Significativo: $P<0,05 / 4 / 6=0,0021 ;$ n.s. = não significativo: $P^{3} 0,05 / 4 / 6=0,0021$.

$1 F N T=$ Brachiaria decumbens hay; $F N T+U=$ not treated hay + urea; $F T B+U=$ hay innoculated with Pleurotus ostreatus + urea; $F T Q+F N T=$ urea-ammoniated hay+ not treated hay.

$21=F N T$ versus $F N T+U ; 2=F N T+U$ versus $F B T+U ; 3=F N T+U$ versus $F T Q+F N T ; 4=F T B+U$ versus $F T Q+F N T$;

$3 D M=$ dry matter; $C P=$ crude protein; $N D F=$ neutral detergent fiber; $A D F=$ acid detergent fiber; $H E M=$ hemicellulose; $C E L=$ cellulose;

$4 F T Q=$ values for ammoniated hay, calculated by difference.

$5 E P=$ standard error of mean.

${ }^{*}$ Significant: $P<0.05 / 4 / 6=0.0021 ;$ n.s. $=$ non significant: $P^{3} 0.05 / 4 / 6=0.0021$
} 
redução na digestão da parede celular, sendo esse efeito atribuído ao menor tempo de permanência de forragens moídas no trato gastrointestinal.

Okamoto et al. (1992) avaliaram o tratamento da palha de arroz com o fungo $P$. ostreatus e verificaram aumento na digestibilidade in vitro da matéria seca de 25,5 para $37,5 \%$, enquanto a digestibilidade in vivo com carneiros diminuiu de 52,0 para 42,7\%. Os autores afirmam que a razão desta discrepância não está clara, mas pode ser atribuída à maior fragilidade na estrutura da fibra, em consequiência da redução no teor de hemicelulose.

Com base nas Tabelas 2 e 3, calculou-se o consumo de MS digestível. As médias para as dietas FNT, FNT+U, FTB+U e FTQ+FNT foram: 0,70; 0,$79 ; 0,76$; e $0,82 \%$ do $\mathrm{PV}$, respectivamente, não sendo verificada diferença estatística entre estas. $\mathrm{O}$ maior valor de consumo verificado para o $\mathrm{FTB}+\mathrm{U}$ foi prejudicado pela menor digestibilidade desta dieta, $\mathrm{o}$ que refletiu diretamente no consumo de MS digestível.

Vale ressaltar que as diferenças esperadas com os tratamentos químico ebiológico sob a melhora da qualidade do feno, mais especificamente com a amonização, e com issomelhora na digestibilidade da MS, foram sempre comparados com o FNT + U, pois, dessa maneira, igualase às condições para comparação a nível de nitrogênio disponível para os microorganismo do rúmen. Vários trabalhos publicados encontrados na literatura apresentam realmente melhora na digestibilidade com a amonização, mas, na maioria das vezes, a comparação é realizada sem corrigir o nível protéico do feno não tratado em relação ao tratado com uréia.

Balanço de $N$

O balanço de nitrogênio, em $\mathrm{g} / \mathrm{kg}$ de peso vivo/dia e g/kg de peso metabólico, está apresentado na Tabela 5 .

Tabela 4 - Distribuição de partículas nas peneiras (\% do feno retido na tela)

Table 4 - Particle distribution on sieves (\% of hay retained on screen)

\begin{tabular}{cccc}
\hline $\begin{array}{c}\text { Abertura da peneira }(\mathrm{mm}) \\
\text { Screen size }(\mathrm{mm})\end{array}$ & $\begin{array}{c}\text { Feno não tratado } \\
\text { Not treated hay }\end{array}$ & $\begin{array}{c}\text { Feno inoculado com P. ostreatus } \\
\text { Hay innoculated with P. ostreatus }\end{array}$ & $\begin{array}{c}\text { Feno amonizado com uréia } \\
\text { Urea-ammoniated hay }\end{array}$ \\
\hline 4,00 & 24,65 & 2,22 & 4,56 \\
2,00 & 15,55 & 4,21 & 13,75 \\
1,41 & 19,99 & 6,74 & 21,83 \\
1,00 & 13,02 & 9,42 & 15,50 \\
0,50 & 16,00 & 23,92 & 22,03 \\
Fundo & 10,79 & 53,49 & 22,33 \\
Pan & & & \\
\hline
\end{tabular}

Tabela 5 - Balanço diário de nitrogênio, em $\mathrm{g} / \mathrm{kg}$ de peso vivo (PV) e por unidade de peso metabólico $\left(\mathrm{PV}^{0,75}\right)$

Table 5 - Daily nitrogen balance, in $\mathrm{g} / \mathrm{kg}$ of body weight (BW) and metabolic body weight (BW.75) and change in body weight (g/day)

\begin{tabular}{|c|c|c|c|c|c|c|c|c|c|}
\hline \multirow{2}{*}{$\begin{array}{l}\text { Balanço de } \mathrm{N} \\
N \text { balance }\end{array}$} & \multicolumn{4}{|c|}{$\begin{array}{c}\text { Dietas }^{1} \\
\text { Diet }^{1}\end{array}$} & \multirow[b]{2}{*}{$\mathrm{EP}^{3}$} & \multicolumn{4}{|c|}{$\begin{array}{c}\text { Contrastes }^{2} \\
\text { Contrasts }^{2}\end{array}$} \\
\hline & FNT & $\mathrm{FNT}+\mathrm{U}$ & $\mathrm{FTB}+\mathrm{U}$ & FTQ+FNT & & 1 & 2 & 3 & 4 \\
\hline $\mathrm{g} / \mathrm{kg} \mathrm{PV} / \mathrm{dia}$ & $-0,03$ & 0,03 & 0,02 & 0,02 & 0,014 & $* *$ & n.s. & n.s. & n.s. \\
\hline $\mathrm{g} / \mathrm{kg} B W / d a y$ & & & & & & & & & \\
\hline $\begin{array}{l}\mathrm{g} / \mathrm{kg} \mathrm{PV} 0,75 / \mathrm{dia} \\
\mathrm{g} / \mathrm{kgB} W^{.75} / \text { day }\end{array}$ & $-0,08$ & 0,08 & 0,06 & 0,06 & 0,034 & $* *$ & n.s. & n.s. & n.s. \\
\hline
\end{tabular}

1 FNT = feno de Brachiaria decumbens não tratado; FNT+U = feno não tratado+uréia; FTB+U = feno inoculado com Pleurotus ostreatus + uréia; FTQ+FNT = feno amonizado com uréia + feno não tratado.

$21=\mathrm{FNT}$ versus FNT + U; $2=\mathrm{FNT}+\mathrm{U}$ versus FTB + U; $3=\mathrm{FNT}+\mathrm{U}$ versus FTQ + FNT; $4=\mathrm{FTB}+\mathrm{U}$ versus FTQ + FNT;

3 EP = erro-padrão da média.

** Significante: $P<0,05 / 4 / 2=0,00625 ;$ n.s. = não significante: $P \geq 0,05 / 4 / 2=0,00625$

$1 F B=$ not treated Brachiaria decumbens hay; $F N T+U=$ not treated hay + urea; $F T B+U=$ hay innoculated with Pleurotus ostreatus + urea; $F=B$. decumbens hay ammoniated with urea $+B$. decumbens hay.

$21=F B$ versus $F B U ; 2=F B U$ versus $F B F ; 3=F B U$ versus FBAU; $4=$ FBF versus FBAU.

$3 E P=$ standard error of mean.

** Significant: $P<0.05 / 4 / 2=0.00625 ;$ n.s. $=$ not significant $(P \geq 0.05 / 4 / 2=0.00625)$.

\section{R. Bras. Zootec., v.32, n.6, p.2040-2049, 2003 (Supl. 2)}


Observou-se apenas efeito da adição de uréia sobre o balanço de nitrogênio nas dietas com aproximadamente $8 \% \mathrm{~PB}$, o balanço ficou muito próximo a zero. Huntington \& Archibeque (1999) afirmam que ruminantes conseguem sobreviver com dietas de baixo teor protéico, devido à reciclagem de nitrogênio para manutenção da função ruminal, em situações de balanço negativo de nitrogênio. Ferreira et al. (1990) verificaram balanço negativo de compostos nitrogenados em animais alimentados com palha de arroz não tratada, relacionando este efeito à combinação de baixo teor de PB digestível e baixo teor de energia digestível do resíduo.

\section{Conclusões}

O tratamento biológico dos fenos de Brachiaria decumbens de baixa qualidade diminuiu o teor de parede celular, aumentou a friabilidade do feno e o consumo, mas diminuiu a digestibilidade, provavelmente em decorrência da redução no tamanho médio das partículas e do aumento no teor de lignina da pare de celular. Em virtude do antagonismo entre estes resultados, não melhorou o valor nutritivo do feno.

O tratamento químico com uréia mostrou tendência em aumentar o consumo e a digestibilidade da celulose. Também aumentou a friabilidade do feno, embora em menor grau que o tratamento biológico.

Sugere-se que o tratamento biológico seja melhor investigado, principalmente no tocante aos efeitos da moagem no tamanho das partículas; tempo de incubação e micélio fúngicos que atuem na degradação da lignina.

\section{Literatura Citada}

ADAMOVIC, M.; GRUBIC, G.; MILENKOVIC, I. et al. The biodegradation of wheat straw by Pleurotus ostreatus mushrooms and its use in cattle feeding. Animal Feed Science Technology, v.71, p.357-362, 1998.

ASSOCIATION OF OFFICIAL ANALYTICAL CHEMISTS AOAC. Official methods of analysis. 15.ed. Arlington, Virginia, 1990. v.1, 1298p.

BALLET, N; BESLE, J.M.; DEMARQUILLY, C. Effect of ammonia and urea treatments on digestibility and nitrogen content of dehydrated lucerne. Animal Feed Science Technology, v.67, p.69-82, 1997.

BERGER, L.L.; FAHEY, G.C; BOURQUIN, L.D. et al. Modification of forage after harvest. In: FAHEY, D.C. (Ed.) Forage quality, evaluation, and utilization. 1.ed. Madison: American Society of Agronomy, Crop Science Society, Soil Science Society, 1994. p.922-966.
BISARIA, R.; MADAN, M.; VASUDEVAN, P. Utilization of agro-residues as animal feed through bioconversion. Bioresource Technology, v.59, p.5-8, 1997.

BROWN, W.F.; ADJEI, M.B. Urea ammoniation effects on the feeding value of Guineagrass (Panicum maximum) hay. Journal of Animal Science, v.73, p.3085-3093, 1995.

FERREIRA, J.Q.; GARCIA, R.; DA SILVA, D.J. et al. Avaliação da palha de arroz tratada com amônia anidra em ensaio de digestibilidade com ovinos. Revista da Sociedade Brasileira de Zootecnia, v.19, n.4, p.315-320, 1990.

FISHER, R.A.; YATES, F. Tabelas estatísticas para pesquisa em biologia, medicina e agricultura. 1.ed. São Paulo: EDUSP e Polígono, 1971. 150p.

HUGUES, N.R.G.; VALLE, C.B.; HERRERO, M. Estimativa de resistência ao cisalhamento e à moagem em quatro espécies de Brachiaria. In: REUNIÃO ANUAL DA SOCIEDADE BRASILEIRA DE ZOOTECNIA, 35.,1998, Botucatu. Anais... São Paulo: Gnosis, 1998, CD-ROM. Forragicultura. FOR-047.

HUNTINGTON, G.B.; ARCHIBEQUE, S.L. Pratical aspects of urea and ammonia metabolism in ruminants. In: PROCEEDINGS OF THE AMERICAN SOCIETY OF ANIMAL SCIENCE. 1999. http://www.asas.org/jas/symposia/ proceedings/0939.pdf (17/02/2002).

MOYSON, E.; VERACHTERT, H. Growth of higher fungi on wheat straw and their impact on the digestibility of the substrate. Applied Microbiology and Biotechnology, v.36, p.421-424, 1991.

NATIONAL RESEARCH COUNCIL - NRC. Nutrient requirements of beef cattle. 7.ed. Washington, D.C.: Academy Press: 1996. 242p.

NATIONAL RESEARCH COUNCIL - NRC. Predicting feed intake of food-producing animals. Washington, D.C.: 1987. 85p.

NATIONAL RESEARCH COUNCIL - NRC. Urea and other nonprotein nitrogen compounds in animal nutrition. 1.ed. Washington, D.C.: 1976. p.38-87.

NICOLINI, L.; VOLPE, C.; PEZZOTTI, A. et al. Changes in invitro digestibility of orange peels and distillery grape stalks after solid-state fermentation by higher fungi. Bioresource Technology, v.45, p.17-20, 1993.

OKAMOTO, M.; YAMAKAWA, M.; ABE, H. Improvement of nutritive value of cereal straw by solid state fermentation using Pleurotus ostreatus. Tropical Agriculture Research Series, v.25, p.178-185, 1992.

PEREIRA, J.C.; QUEIROZ, A.C.; MATTOSO, J. et al. Efeito do tratamento da palha de milho e do bagaço de cana, com uréia e amônia anidra, sobre o consumo e ganho de peso de novilhos. Revista da Sociedade Brasileira de Zootecnia, v.19, n.6, p.469-475, 1990.

REIS, R.A.; RODRIGUES, L.R.A.; PEDROSO, P. Avaliação de fontes de amônia para o tratamento de volumosos de baixa qualidade. Revista da Sociedade Brasileira de Zootecnia, v.24, n.4, p.486-493, 1995.

REIS, R.A.; RODRIGUES, L.R.A.; PEREIRA, J.R.A. Sementes de gramíneas forrageiras. In: SIMPÓSIO SOBRE NUTRIÇÃO DE BOVINOS, 6., 1996, Piracicaba. Anais... Piracicaba: Fundação de Estudos Agrários "Luiz de Queiroz", 1996. p.259-280.

REIS, R.A.; RODRIGUES, L.R.A. Amonização de volumosos. Jaboticabal: Fundação de Estudos e Pesquisas em Agronomia, Medicina Veterinária e Zootecnia, 1993. 22p.

REIS, R.A.; RODRIGUES, L.R.A.; PEREIRA, J.R.A. et al. Composição química e digestibilidade de fenos tratados com 
amônia ou uréia. Revista Brasileira de Zootecnia, v.30, n.3, p.666-673, 2001a.

REIS, R.A.; RODRIGUES, L.R.A.; RESENDE, K.T. et al. Avaliação de fontes de amônia para o tratamento de fenos de gramíneas tropicais. 2. Compostos nitrogenados. Revista Brasileira de Zootecnia, v.30, n.3, p.682-686, 2001 b.

ROSA, B.; REIS, R.A.; RESENDE, K.T. et al. Valor nutritivo do feno de Brachiaria decumbens Stapf cv. Basilisk submetido a tratamento com amônia anidra ou uréia. Revista Brasileira de Zootecnia, v.27, n.4, p.815-822, 1998.

SCHMIDT, P.; WECHSLER, F.S.; NASCIMENTO, J.S. et al. Efeito do pré-tratamento na degradação da fração fibrosa do feno de braquiária pelo fungo Pleurotus ostreatus. Revista Brasileira de Zootecnia, v.32, n.6, p.1866-1871, 2003. (Supl. 2)

SCHNEIDER, B.H.; FLATT, P.W. The evaluation of feeds through digestibility experiments. 1.ed. Athens: The University of Georgia Press, 1975. 423p.
SHEN, H.S.; SUNDSTOL, F.; NI, D.B. Studies on untreated and urea-treated rice straw from three cultivation seasons 2 . Evaluation of straw quality through in vitro gas production and in sacco degradation measurements. Animal Feed Science and Technology, v.74, p.193-212, 1998.

SILVA, D.J. Análise de alimentos (Métodos químicos e biológicos). 2.ed. Viçosa, MG: Universidade Federal de Viçosa, 1990. 160p.

STATISTICAL ANALYSIS SYSTEM - SAS. User's guide: statistics. version 6.1. 5.ed. Cary: 1996. 622p.

Van SOEST, P.J. Nutritional ecology of the ruminant. 2.ed. New York: Cornell University Press, 1994. 476p.

Recebido em: 18/11/02 Aceito em: 16/05/03 